DOI: https://doi.org/10.24867/04GI05Adamovic

\title{
ANALIZA POSLOVNIH POKAZATELJA U PREDUZEĆU „LINDE GAS SRBIJA AD BEČEJ“
}

\section{ANALYSIS OF BUSINESS INDICATORS IN THE COMPANY „LINDE GAS SRBIJA AD BEČEJ“}

\author{
Jovana Adamović, Fakultet tehničkih nauka, Novi Sad
}

\section{Oblast - INDUSTRIJSKO INŽENJERSTVO I MENADŽMENT}

Kratak sadržaj - Predmet finansijske analize su finansijski izveštaji, pre svega bilans stanja $i$ bilans uspeha. Racio analiza podrazumeva jedan od instrumenata finansijske analize koji je najčešće u upotrebi. Zadatak ovog istraživanja jeste da se utvrdi uspešnost poslovanja $i$ finansijski položaj preduzeća „Linde gas Srbija AD Bečej“, a pokazatelji koji su korišćeni prilikom analize uključuju pokazatelje likvidnosti, zaduženosti, aktivnosti, ekonomičnosti, rentabilnosti $i$ profitabilnosti. Dobijeni rezultati su obrađeni i polazeći od prethodno definisanih problema, , jedan od osnovnih ciljeva istraživanja jeste da se utvrdi značaj analize poslovnih pokazatelja za prevazilaženje problema koji se odnose na finansijske $i$ operativne performanse posmatranog preduzeća, i utvrde mere za prevazilaženje istih. Nakon obrađenih rezultata, postavljene su hipoteze na osnovu kojih su se dobijali potrebni zaključci.

Ključne reči: analiza finansijskih izveštaja u privrednim društvima, bilans stanja, bilans uspeha, racio pokazatelji.

Abstract - Subjects of financial analysis are financial statements, primarily balance sheet and profit and loss statement. Racio analysis implies one of the most commonly used financial analyses tools. The task of this research is to determine the business performance and financial position of the company ,Linde gas Srbija AD Bečej", and the indicators used in the analysis are indicators of liquidity, indebtedness, activity, economy and profitability. The obtained results are processed and based on previosly defined problems, one of the basic goals of the research is to determine the importance of analyzing business indicators to overcome the problems related to the financial and operational performance of the observed company, and determine the measures for overcoming them. After processed the results, hypotheses were set on which the necessary conclusions were made.

Key words: analysis of financial statements, profit and loss statement, bilans uspeha, racio indicators.

\section{NAPOMENA:}

Ovaj rad proistekao je iz master rada čiji mentor je bila dr Andrea Ivanišević, vanr.prof.

\section{UVOD}

Finansijska analiza obuhvata detaljno istraživanje, kvantificiranje, deskripciju i ocenu finansijskog statusa i uspešnosti poslovanja privrednog društva [1]. Rad u uvodnom delu ukazuje na teorijske osnove analize finansijskih izveštaja u privrednim društvima, koje uključuju pojam privrednih društava, finansijskih izveštaja - bilans stanja i bilans uspeha, kao i finansijsku racio analizu i njen uticaj na planiranje poslovanja preduzeća. U ovom radu analiziraćemo finansijske (poslovne) pokazatelje $u$ preduzeću „Linde gas Srbija AD Bečej“ koji se odnose na likvidnost, zaduženost, efikasnost upravljanja (aktivnost), ekonomičnost, rentabilnost i profitabilnost.

$\mathrm{U}$ nastavku rada analiziraćemo istraživački deo koji obuhvata razloge, odnosno probleme istraživanja, kao i predmet i ciljeve istraživanja i uticaj analize poslovnih pokazatelja za analizu finansijskog položaja i uspešnosti poslovanja preduzeća, utvrđivanje finansijskih i operativnih problema, davanje predloga rešenja problema i ukazivanja njihovog uticaja na planiranje budućih aktivnosti i menadžment odluka preduzeća. Nakon postavljenih hipoteza, odnosno pretpostavki objašnjeni su instrumenti koji su korišćeni u tom procesu, kao i način obrade dobijenih podataka. Podaci su dobijeni komparativnom metodom, na osnovu finansijskih izveštaja dostupnih na sajtu Agencije za privredne registre Republike Srbije.

U završnom delu rada prikazan je predlog mera za unapređenje i poboljšanje dobijenih rezultata koji mogu imati negativan uticaj na proces poslovanja posmatranog preduzeća, kao i sveobuhvatni komentar na definisanu temu rada. U završnom delu rada su izneti zaključci autora kao i njegovo celokupno viđenje na zadatu temu, uz dodatak korišćene literature i izvora koji su bili sastavni deo izrade rada.

\section{ANALIZA FINANSIJSKIH IZVEŠTAJA U PRIVREDNIM DRUŠTVIMA}

Analiza finansijskih izveštaja, odnosno finansijska analiza sastavlja se u poslovne i naučne svrhe. Korišćenjem analize finansijskih izveštaja u poslovne svrhe se utvrđuju rezultati upotrebe resursa pod uticajem kvalitativnih faktora koji potiču iz preduzeća kao i iz njegovog užeg i šireg okruženja. U svakom preduzeću važan je razvoj karijere, a značajne posledice na razvoj karijere imaju sledeće karakteristike: pol, radno iskustvo, materijalno 
stanje i savesnost [2]. U praksi se često za privredno društvo koriste termini: pravno lice, privredni subjekt, firma, preduzeće, kompanija i slično iako ovi termini nemaju isto značenje. Iako se najčešće pod pravnim licima podrazumevaju privredna društva, u pravna lica spadaju i ustanove, udruženja i javna pravna lica koja nemaju iste ciljeve.

Prema Zakonu o privrednim društvima objavljenom 2011. godine: „Privredno društvo je pravno lice koje obavlja delatnost u cilju sticanja dobiti“. Pravno lice je daleko širi pojam u odnosu na privredno društvo i obuhvata i one pravne entitete čiji glavni ciljevi nisu komercijalni ili oni koji nemaju zakonsku obavezu sastavljanja finansijskih izveštaja. Pravne forme privrednih društava prema Zakonu o privrednim društvima Republike Srbije su društva lica- društva sa neograničenim rizikom (ortačko i komanditno društvo), i društva kapitala- društva sa ograničenim rizikom (društvo sa ograničenom odgovornošću i akcionarsko društvo).

\section{Preduzeće ima sledeća obeležja:}

- preduzeće ima svoju ekonomiju;

- ekonomiju ostvaruje u okruženju sa kojim je u permanentnoj komunikaciji;

- preduzeće je složen, dinamički ekonomski sistem;

- preduzeće je poslovno-finansijski entitet, te se kao takav rukovodi, pre svega, poslovno finansijskim ciljevima;

- procesima i pojavama u preduzeću upravlja kompetentan menadžment [3].

Bilans ili finansijski izveštaj je dvostrani, brojčani, finansijski iskaz o svemu čime preduzeće raspolaže, sve ono što je rukovodstvo ostvarilo i sve što se stavlja vlaasniku-cima stavlja na raspolaganje. Kompanije deluju kao sastavni deo svog okruženja, te stoga zavise od promena koje se dešavaju u okruženju. [4] Kako preduzeća sve više uključuju informacije od svojih klijenata $\mathrm{u}$ procese kreiranja proizvoda ili usluga [5], neophodno je da uvek imaju uvid u svoje finansijske rezultate i shodno tome prilagode intenzitet aktivnog uključenja klijenata tokom kampanja razvoja i unapređenja proizvoda ili usluga.

Kupac je uvek bio i ostao prioritet u razvoju novog proizvoda, prilikom čega je potrebno razumeti njegove zahteve i očekivanja. Ključ uspeha je timski rad, koordiniran rad na povezivanju ideja i razumevanje želja i potreba kupaca, što je ujedno i primarna svrha otvorenih inovacija. Bilans stanja je trenutna slika finansijskog položaja neke kompanije na određeni dan. On prikazuje veličinu i strukturu sredstava i izvora finansiranja. [6] Bilans uspeha je računovodstveni izveštaj u kojem su iskazani ostvareni prihodi $\mathrm{i}$ rashodi preduzeća $\mathrm{u}$ određenom obračunskom periodu. [7] Osnovni finansijski izveštaji podvrgavaju se analitičkom ispitivanju upotrebom odgovarajućih instrumenata finansijske analize.

Racio analiza je jedan od instrumenata finansijske analize koji se najčešće koristi, a zadatak ovog istraživanja jeste pre svega da se utvrdi finansijski položaj i uspešnost poslovanja posmatranog preduzeća. Zanimljivo je posmatrati finansijske pokazatelje (likvidnosti, zaduženosti, aktivnosti i profitabilnosti) na primeru akcionarskog društva iz Republike Srbije, naročito što određena istraživanja [8] pokazuju da je srpsko tržište kapitala nestabilno i nosi visok investicioni rizik. Finansijsko planiranje znači predviđanje, usmeravanje, usklađivanje i unapred proračunato raspoređivanje elemenata finansijske funkcije u preduzeću [9] - Finansijski plan predstavlja značajan izvor informacija o poslovanju preduzeća, naročito što svaka uspešna poslovna analiza zahteva razumevanje poslovnih vrednosti [10], te je neophodno razumeti i finansijsku poziciju preduzeća. U ovom trenutku je od presudnog značaja razumeti poslovnu logiku kompanije i njene osnovne delatnosti. Pomoću finansijskih pokazatelja dobijaju se informacije koje se odnose na likvidnost, zaduženost, ekonomičnost, efikasnost upravljanja, rentabilnost i profitabilnost. Moguće je utvrditi finansijski položaj, kao i uspešnost poslovanja preduzeća što je osnova za buduće menadžment odluke i planiranje budućih aktivnosti u okviru poslovanja preduzeća. Kako model poslovanja objašnjava na koji način preduzeće kreira i pruža vrednost svojim klijentima [11], utvrđivanje finansijskog položaja preduzeća je veoma značajno za kvalitetno donošenje odluka.

\section{ISTRAŽIVANJE}

Finansijska analiza se bavi istraživanjem, kvantificiranjem, opisivanjem i ocenjivanjem finansijskog položaja i uspešnosti poslovanja preduzeća. Na osnovu analize su identifikovani problemi koji se odnose na smanjenje likvidnosti u posmatranom periodu, smanjenje ekonomičnosti finansiranja i smanjenje obrta gotovih proizvoda, robe i potraživanja od kupaca.

U skladu sa definisanim problemom, predmet istraživanja u master radu je analiza poslovnih pokazatelja pomoću finansijskih izveštaja kako bi se utvrdilli uzroci navedenih problema, definisale mere za njihovo rešenje i uticaj navedenih mera na menadžment odluke preduzeća i planiranje budućih poslovnih aktivnosti. Jedan od ciljeva istraživanja jeste da se utvrdi značaj analize poslovnih pokazatelja za prevazilaženje problema koji se odnose na finansijske i operativne performanse posmatranog preduzeća, i utvrde mere za prevazilaženje istih Opšta hipoteza istraživanja postavljena je u skladu sa problemom, predmetom i ciljem istraživanja i glasi: „Upotreba finansijske analize može biti od pomoći za sagledavanje uspešnosti, finansijskog položaja preduzeća i menadžment odluka u preduzeću Linde gas Srbija AD Bečej“".

$\mathrm{Na}$ osnovu opšte hipoteze su definisane i pojedinačne hipoteze:

PH1- „Preduzeće Linde gas Srbija AD Bečej ima zadovoljavajući finansijski položaj.“

PH2- „Preduzeće Linde gas Srbija AD Bečej ostvaruje uspešnost u poslovanju.““

Istraživanje je sprovedeno u kompaniji „Linde gas Srbija AD Bečej“. Korišćeni su bilans stanja i bilans uspeha preduzeća, kako bi se na osnovu izračunatih poslovnih (finansijskih) pokazatelja utvrdio njegov finansijski položaj i uspešnost poslovanja. Osim iz finansijskih izveštaja, dobijene su informacije i od zaposlenih koje se 
odnose na finansijske i operativne probleme koji nastaju prilikom obavljanja redovnih poslovnih aktivnosti. Rezultati istraživanja uključuju deo koji se odnosi na informacije o preduzeću „Linde gas Srbija AD Bečej“ i njegovom lancu vrednosti i deo koji se odnosi na poslovne pokazatelje (finansijska racio analiza).

U prvom delu prikazana je vlasnička struktura preduzeća, delatnosti u kojima posluje i najznačajniji proizvodi. Takođe, prikazan je i lanac vrednosti preduzeća u okviru kog su opisane primarne i sekundarne aktivnosti koje učestvuju u kreiranju vrednosti, kao i najznačajniji kupci i dobavljači ovog preduzeća. U delu koji obuhvata poslovne pokazatelje (finansijska racio analiza) izvršena je analiza racia likvidnosti, racia zaduženosti, racia aktivnosti, racia ekonomičnosti, racia rentabilnosti i racia profitabilnosti. Kompanija „Linde gas Srbija AD Bečej“ posluje u brojnim delatnostima, a najznačajniji proizvodi kompanije uključuju: atmosferske gasove , gorivne gasove, zaštitne gasove, elektronske gasove i hemikalije, hlađenje prehrambenih proizvoda, zamrzavanje hrane, gasove kvaliteta za hranu, gasne smeše, rashladne fluide, $\mathrm{u}$ farmaceutskoj industriji kontrolu temperature fluida $\mathrm{i}$ kontrolu emisije pare, proizvode za zavarivanje,i proizvode za prečišćavanje vode. Pokazatelji likvidnosti uključuju pokazatelje trenutne likvidnosti, ubrzane likvidnosti, tekuće likvidnosti i solventnosti.

U posmatranom periodu, od 2014. do 2016. godine su zadovoljene referentne vrednosti ovih pokazatelja, osim za pokazatelj trenutne i tekuće likvidnosti u 2016. godini. Primećujemo pad racia trenutne likvidnosti u periodu od 2014. do 2016. godine, a u 2016.-toj godini preduzeće ne uspeva da podmiri dospele obaveze upotrebom najlikvidnije imovine. Posmatrajući racio ubrzane likvidnosti i racio tekuće likvidnosti, možemo uočiti njegov pad u periodu od 2014. do 2016. godine. Zaključujemo da preduzeće u sve manjoj meri može izmirivati svoje obaveze upotrebom gotovine, gotovinskih ekvivalenata, potraživanja i obrtne imovine. Pokazatelji zaduženosti uključuju koeficijent finansijskog leveridža, koeficijent sopstvenog finansiranja, faktor zaduženosti i indikator samostalnosti finansiranja.

Pokazatelj zaduženosti finansijski leveridž, i faktor zaduženosti preduzeća imaju niske vrednosti što ukazuje na nisku zaduženost preduzeća. Koeficijent sopstvenog finansiranja pokazuje učešće sopstvenog kapitala u ukupnom kapitalu. On bi trebao biti veći od 0,50 (50\%), a $\mathrm{u}$ posmatranom periodu samo je u 2015. godini zadovoljena referentna vrednost ovog pokazatelja. Posmatrajući indikator sopstvenog finansiranja možemo zaključiti da preduzeće oko $90 \%$ svog poslovanja finansira iz sopstvenih izvora, dok iz tuđih (pozajmljenih) izvora svega $10 \%$. Pokazatelji aktivnosti (obrta) se odnose na brzinu obrta materijala, nedovršene proizvodnje, gotovih proizvoda, robe i potraživanja od kupaca.

U posmatranom periodu, od 2014. do 2016. godine dolazi do pada koeficijenta obrta zaliha (materijala, gotovih proizvoda i robe), a povećanja vremena obrta. Preduzeće ne poseduje zalihe nedovršene proizvodnje. Pokazatelj koji se odnosi na brzinu obrta potraživanja od kupaca takođe ukazuje na nizak koeficijent obrta, a povećanje vremena da se napravi jedan obrt. Dolazi do opadanja prihoda po osnovu prodaje, a povećanja potraživanja od kupaca. Pokazatelji ekonomičnosti podrazumevaju indikator ekonomičnosti ukupnog poslovanja, indikator ekonomičnosti redovnog poslovanja $\mathrm{i}$ indikator ekonomičnosti finansiranja. Indikator ekonomičnosti ukupnog poslovanja i indikator ekonomičnosti redovnog poslovanja beleže blagi rast u posmatranom periodu, dok se vrednost indikatora ekonomičnosti finansiranja kreće iznad referentne vrednosti, ali se beleži značajan pad vrednosti ovog pokazatelja od 2014. do 2015. godine.

Racia rentabilnosti ukupnog i sopstvenog kapitala beleže rast u posmatranom periodu, kao i stopa poslovne dobiti kao rezultat rasta poslovnog dobitka i poslovnih prihoda. Pokazatelji profitabilnosti uključuju bruto maržu profita, neto maržu profita i neto rentabilnost imovine.Ovi pokazatelji beleže rast, te zaključujemo da je finansijski položaj sa stanovišta profitabilnosti zadovoljavajući.

\section{DISKUSIJA REZULTATA ISTRAŽIVANJA}

Na osnovu cilja istraživanja koji smo postavili, potrebno je izvršiti analizu poslovnih pokazatelja u preduzeću, a da se izvedu neophodni zaključci, potrebno je da opštu hipotezu „Upotreba finansijske analize može biti od pomoći za sagledavanje uspešnosti, finansijskog položaja preduzeća i menadžment odluka u preduzeću Linde gas Srbija AD Bečej“" potvrdimo ili opovrgnemo.

Iz tog razloga je potrebno pojedinačno izvršiti analizu svih navedenih poslovnih (finansijskih) pokazatelja, kako bismo dobili rezultate kojima se dokazuju pojedinačne hipoteze. Da bismo mogli utvrditi da li je pojedinačna hipoteza (PH1) koja glasi -PH1- „Preduzeće Linde gas Srbija AD Bečej ima zadovoljavajući finansijski položaj“ potvrđena ili ne, moramo izvesti zaključak na osnovu dobijenih vrednosti pokazatelja likvidnosti, zaduženosti i aktivnosti (efikasnosti upravljanja). Svi dobijeni rezultati koji se odnose na likvidnost opadaju u dinamici $u$ posmatranom periodu, uključujući i solventnost. Zaključujemo da se smanjuje likvidnost preduzeća, kao i solventnost u posmatranom periodu. Preduzeće ima zadovoljavajuću likvidnost, ali ona opada iz godine $u$ godinu. Iz tog razloga potrebno je analizirati finansijski položaj sa stanovišta likvidnosti, kao i analizirati finansijske probleme usled kojih je došlo do njenog opadanja. Kako bi se rešio problem smanjenja likvidnosti, potrebno je preispitati visinu i strukturu obrtnih sredstava (zaliha i potraživanja), kao i visinu i rokove dospeća kratkoročnih obaveza. U periodu od 2014. do 2016. godine, došlo je do rasta zaliha i potraživanja od kupaca, što je pozitivan trend koji rezultira povećanju racia likvidnosti. Međutim, $u$ datom periodu dolazi i do značajnog rasta kratkoročnih obaveza, zbog rasta obaveza prema dobavljačima $u$ zemlji $i \mathrm{u}$ inostranstvu. Do značajnijeg rasta obaveza prema dobavljačima u zemlji dolazi u periodu od 2014. do 2015. godine, dok do značajnijeg rasta obaveza prema dobavljačima u inostranstvu dolazi u periodu od 2015. do 2016.godine. U cilju povećanja racia likvidnosti, potrebno je smanjenje kratkoročnih obaveza prema dobavljačima u zemlji i inostranstvu. Sa stanovišta zaduženosti finansijski položaj preduzeća je zadovoljavajući, jer dobijeni rezultati ukazuju na nisku zaduženost i nisku rizičnost ulaganja $u$ preduzeće. Analizom pokazatelja aktivnosti utvrđeno je da postoji potreba za poboljšanjem finansijskog položaja preduzeća i za identifikovanjem problema koji utiču na smanjenje efikasnosti upravljanja u preduzeću. 
Na osnovu dobijenih rezultata zaključujemo da preduzeće sa stanovišta likvidnosti i zaduženosti ostvaruje zadovoljavajući finansijski položaj a sa stanovišta aktivnosti treba da ga poboljša, te je hipoteza koja glasi "Preduzeće Linde gas Srbija AD Bečej ima zadovoljavajući finansijski položaj" potvrđena. Ipak, postoje i problemi koji mogu narušiti finansijski položaj, u smislu likvidnosti i efikasnosti upravljanja ukoliko se ne preduzmu mere za njihovo prevazilaženje.

Da bismo mogli utvrditi da li je pojedinačna hipoteza (PH2) koja glasi -PH2- „Preduzeće Linde gas Srbija AD Bečej ostvaruje uspešnost u poslovanju“ potvrđena ili ne, moramo izvesti zaključak na osnovu dobijenih vrednosti pokazatelja ekonomičnosti, rentabilnosti i profitabilnosti. $\mathrm{Na}$ osnovu dobijenih rezultata zaključujemo da preduzeće sa stanovišta ekonomičnosti, rentabilnosti i profitabilnosti ostvaruje zadovoljavajući finansijski položaj, pa se može zaključiti da je hipoteza koja glasi „Preduzeće Linde gas Srbija AD Bečej ostvaruje uspešnost u poslovanju“ potvrđena. Analizom ovih pokazatelja utvrđen je problem koji se odnosi na smanjenje ekonomičnosti finansiranja zbog rasta rashoda finansiranja. Analizom navedenih rezultata kao i analizom pojedinačnih hipoteza, zaključuje se da je i postavljena opšta hipoteza „Upotreba finansijske analize može biti od pomoći za sagledavanje uspešnosti, finansijskog položaja preduzeća i menadžment odluka u preduzeću Linde gas Srbija AD Bečej“ potvrđena.

\section{ZAKLJUČNA RAZMATRANJA}

Preduzeće „Linde gas Srbija AD Bečej“, posluje u brojnim oblastima i poseduje kupce koji obavljaju poslovne aktivnosti u različitim delatnostima,jer nudi širok spektar industrijskih, specijalnih i medicinskih gasova. $\mathrm{Na}$ osnovu finansijskih racio pokazatelja , možemo uočiti da kompanija ostvaruje dobre poslovne rezultate u celini, iako se mogu uočiti odstupanja određenih pokazatelja od referentnih vrednosti. Zaključujemo da opada likvidnost iz godine u godinu, a kako bi se reagovalo na vreme potrebno je da se preispita visina i struktura obrtnih sredstava, kao i visina i rokovi dospeća kratkoročnih obaveza. Na osnovu indikatora ekonomičnosti finansiranja, možemo uočiti njegov pad, zbog značajnog rasta finansijskih rashoda usled negativnih kursnih razlika i dugoročnih rezervisanja. Do negativnih kursnih razlika dolazi zbog fluktuacije deviznog kursa, a da bi se finansijski rashodi smanjili potrebno je smanjenje dugoročnih rezervisanja. Posmatrajući operativne performanse preduzeća, uočili smo da postoji problem fizičke odvojenosti jedinice distribucije i prodaje, što ima za posledicu otežano obavljanje ovih aktivnosti. Uočili smo i moguće probleme u magacinu, prilikom evidentiranja nabavke repromaterijala za proizvodnju na osnovu otpremnice da ne dođe do kašnjenja proizvodnje. Pri obračunu proizvodnje, može takođe doći do problema u protoku dokumenatcije između proizvodnje i računovodstva, jer ako ne stigne sva dokumentacija do računovodstvene službe na vreme može doći do neadekvatnog obračuna cene koštanja. Za sve navedene probleme dati su predlozi rešenja. Svako preduzeće teži ka ostvarenju što boljih poslovnih rezultata, i što boljem finansijskom položaju i uspešnosti. Zbog toga stalno mora poboljšavati svoje performanse, i tražiti načine za njihovo unapređenje. Na osnovu izvršene analize, uočili smo određene finansijske i operativne probleme i dali predloge rešenja.

U celini, preduzeće uspešno posluje i ima odgovarajuće poslovne rezultate, zahvaljujući čemu ima konkurentan položaj na domaćem i inostranom tržištu.

\section{LITERATURA}

[1] Knežević G., Stanišić N., Mizdraković V., „Analiza finansijskih izveštaja namenjeno tržištu republike Srbije“, Univerzitet Singidunum, Beograd, 2017., str. 7

[2] Katić I., Ivanišević A., Grubić Nešić L., Penezić N., Effects of Sociodemographic Characteristics and Personality Traits on Career Development, The International Journal of Aging and Human Development, str. 201-216

[3] Samardžić M., Andžić S., „Finansijska analiza revizija“, Beogradska poslovna škola-Visoka škola strukovnih studija, Beograd, 2013., str. 2

[4] Leković B., Ivanišević A., Marić B., Demko-Rihter J.: Assessment of the most significant impacts of environment on the changes in company cost structure, Economic Research, 2013

[5] Leber M., Ivanišević A., Borocki J., Radišić M., Slusarczyk B., „Fostering Alliances with Customers for the Sustainable Product Creation", Sustainability, vol. 10 (9), 2018

[6],[7] Knežević G., „Analiza finansijskih izveštaja“, Univerzitet Singidunum, Beograd, 2008., str. 12/16

[8] Radišić M., Dobromirov D., ,Statistical analysis of price returns of regional stock market indices"،, Transformations in Business\&Economics, vol. 16, no. 3 (42), str. 175-184

[9] Ivanišević A., Katić I., Marjan L., Buchmeister B., Business plan feedback for cost effective business processes, Advances in Production

Engineering\&Management, ISSN 1854-6250 Print, ISSN 1855-6531

[10] Radišić M., Nedeljković A., 5C Model-Business case study solving methodology, New Educational Review, Vol. 27, 1 (2012)., str. 19-30

[11] Bolesnikov M., Popović Stijačić M., Radišić M., Takači A., Borocki J., Bolesnikov D., Bajdor P. and Dzieńdziora J., „Development of a Business Model by Introducing Sustainable and Tailor-Made Value Proposition for SME Clients“, Sustainability, vol. 11 (4), 2019

\section{Kratka biografija:}



Jovana Adamović rođena je 27.06.1993. u Novom Sadu, Republika Srbija. Osnovne akademske studije upisala je na Ekonomskom fakultetu u Subotici 2012. godine, a završila 2017. godine. Master akademske studije upisala je na Fakultetu tehničkih nauka u Novom Sadu 2017. godine, a završila 2019. godine. 